\title{
Artificial Membranes from Multiblock Copolymer IV. Four-Component Pentablock Copolymers of the DSD'AD Type Usable to Fabricate a Charge-Mosaic Membrane
}

\author{
Shin-ichi TAKahashi, Kōsaburo Matsumura, Masatoshi TOdA, \\ Teruo Fujimoto, Hirokazu Hasegawa, ${ }^{*}$ \\ and Yoshiyuki MIYAKI** \\ Department of Materials Science and Technology, Technological University of Nagaoka, \\ Kamitomioka-chō, Nagaoka 949-54, Japan \\ * Department of Polymer Chemistry, Faculty of Engineering, Kyoto University, \\ Kyoto 606, Japan \\ **Central Research Laboratory, Toyo Soda Manufacturing Company, \\ Shin-Nanyo, Yamaguchi 746, Japan
}

(Received April 3, 1985)

\begin{abstract}
Four-component pentablock copolymers of the DSD'AD type, poly(isoprene- $b$ styrene- $b$-butadiene- $b$-(4-vinylbenzyl)dimethylamine- $b$-isoprene) and poly(butadiene- $b$-styrene- $b$ isoprene- $b$-(4-vinylbenzyl)dimethylamine- $b$-butadiene), were prepared by a sequential anionic polymerization and the morphologies of the films cast from benzene, dioxane, and cyclohexane solutions of the samples were studied by electron microscopy and viscoelastic spectrometry. Threelayer lamellar structures were observed for the benzene- and dioxane-cast films just like as the case for ISIAI pentablock copolymers. Charge-mosaic membranes prepared by quaternizing, crosslinking, and sulfonating the films exhibited better refined microstructures and better performance than those prepared from ISIAI block copolymers.
\end{abstract}

KEY WORDS Four-Component Pentablock Copolymer/Poly(isoprene- $b$ styrene- $b$-butadiene- $b$-(4-vinylbenzyl)dimethylamine)- $b$-isoprene) / Poly(butadiene- $b$-styrene- $b$-isoprene- $b$-(4-vinylbenzyl)dimethylamine)- $b$-butadiene) / Sequential Anionic Polymerization / Three-Layer Lamellar Structure / Charge-Mosaic Membrane / Dialysis /

We reported in preceding papers ${ }^{1-3}$ that pentablock copolymers of the ISIAI type, poly(isoprene- $b$-styrene- $b$-isoprene- $b$-(4vinylbenzyl)dimethylamine- $b$-isoprene), form a three-layer lamellar structure of the repeating unit of -I-S-I-A- when they have proper molecular architecture and proper solvents are chosen for the film preparation, and that the films are tougher than those prepared from a triblock copolymer of the SIA type when the separated microdomains are chemically modified. They can be, therefore, used to prepare a charge-mosaic membrane by quaternizing, cross-linking, and sulfonating the $\mathrm{A}, \mathrm{I}$, and $\mathrm{S}$ domains, respectively. ${ }^{4-6}$ In practice, the resulting charge-mosaic membranes exhibited water and salt transport behaviors peculiar to a charge-mosaic membrane. ${ }^{6}$

However, the ion-exchange layers of the membrane prepared were not perpendicular to the membrane surface throughout the membrane but randomly oriented and considerably winding, although this is inevitable to some extent because the layers are extremely thin compared with the thickness of the membrane. The well-defined morphology continuous over 
a long distance is essential for a charge-mosaic membrane of high separation efficiency. In this work, we make a further study on pentablock copolymers of the DSD'AD type in order to find the optimum architecture of the block copolymer utilized for preparing a chargemosaic membrane. Here, the terminal block D and the middle block $\mathrm{D}^{\prime}$ of the pentablock copolymer, which constitute the neutral domains of the charge-mosaic membrane, are composed of different diene monomers with the expectation that such a block copolymer would provide a better refined and tougher lamellar structure than ISIAI block copolymers.

\section{EXPERIMENTAL}

\section{Block Copolymerization}

In this work, two types of pentablock copolymers, poly(isoprene- $b$-styrene- $b$-butadiene- $b$-(4-vinylbenzyl)dimethylamine- $b$-isoprene) (ISBAI type, TUN 1013) and poly(butadiene- $b$-styrene- $b$-isoprene- $b$-(4vinylbenzyl)dimethylamine- $b$-butadiene) (BSIAB type, TUN 1015), were prepared by a sequential anionic polymerization method using benzene and $s$-butyllithium as solvent and initiator, respectively. Each block copolymerization was carried out stepwise by the five-stage addition of monomers: the order of polymerization was isoprene, styrene, butadiene, (4-vinylbenzyl)dimethylamine, and isoprene for TUN 1013 and butadiene, sty- rene, isoprene, (4-vinylbenzyl)dimethylamine, and butadiene for TUN 1015. In this paper, styrene, (4-vinylbenzyl)dimethylamine, isoprene, and butadiene are abbreviated by $S$, A (or 4-VBDMA), I, and B, respectively. Prior to polymerization, styrene, 4-VBDMA, and isoprene were purified by the same methods as described previously ${ }^{7}$ and butadiene was purified by the same method as that for isoprene.

In Table I are listed the amounts of monomers added at each polymerization step, the amounts of initiator, the conversions of the block copolymerizations, and the number average molecular weights $M_{n}$ of the final pentablock copolymers and their precursors. Here, the $M_{n}$ values were determined by osmometry in toluene at $30^{\circ} \mathrm{C}$ with a high-speed membrane osmometer, Hewlett Packard type 502. The conversions were close to $100 \%$ and $M_{n}$ of the precursors and the final polymers were in good agreement with the kinetic molecular weights $M_{\mathrm{k}}$ calculated from the amounts of monomers and initiator used. The kinetic molecular weight $M_{\mathrm{k}}$ of each of the component blocks of the ISBAI and BSIAB pentablock copolymers prepared are listed in Table II. The values of ISIAI pentablock copolymers, TUN 1004 and 1009, are also shown here again for convenience, although they have been reported elsewhere. $^{1,3}$ Each of the samples TUN 1013 and 1015 was designed such that the polymerization degrees of $\mathrm{S}$ and A blocks are almost equal, the total content of polydiene is about

Table I. Preparation of DSD'AD-type pentablock copolymers

\begin{tabular}{|c|c|c|c|c|c|c|c|c|c|c|c|}
\hline \multirow{2}{*}{ Sample code } & \multirow{2}{*}{$\frac{\begin{array}{c}\text { Amount of } \\
\text { initiator }\end{array}}{10^{4} \mathrm{~mol}^{-1}}$} & \multicolumn{5}{|c|}{ Amount of monomer $/ \mathrm{g}$} & \multirow{2}{*}{$\frac{\text { Conversion }}{\%}$} & \multicolumn{4}{|c|}{$M_{n} / 10^{4} \mathrm{~g} \mathrm{~mol}^{-1}$} \\
\hline & & Diene & Styrene & Diene & 4-VBDMA & Diene & & \multicolumn{3}{|c|}{ Precursors } & $\begin{array}{c}\text { Final } \\
\text { polymers }\end{array}$ \\
\hline ISBAI-type & & & & & & & & IS & ISB & ISBA & ISBAI \\
\hline TUN 1013 & 2.10 & 4.4 & 10.5 & 8.3 & 16.0 & 4.3 & 96 & 7.4 & 11.7 & 18.6 & 21.0 \\
\hline BSIAB-type & & & & & & & & BS & BSI & BSIA & BSIAB \\
\hline TUN 1015 & 1.26 & 2.0 & 5.0 & 4.0 & 6.0 & 1.9 & 100 & 6.2 & 9.9 & 13.7 & 15.2 \\
\hline
\end{tabular}


Table II. Average molecular weights $M_{\mathrm{k}}$ of the component blocks of the copolymers

\begin{tabular}{ccccccc}
\hline \multirow{3}{*}{ Sample code } & \multicolumn{5}{c}{$M_{\mathbf{k}} / 10^{4} \mathrm{~g} \mathrm{~mol}^{-1}$} & \begin{tabular}{c} 
Total \\
\cline { 2 - 5 }
\end{tabular} \\
\cline { 2 - 5 } & $M_{\mathbf{k}}(\mathrm{D})$ & $M_{\mathbf{k}}(\mathbf{S})$ & $M_{\mathbf{k}}\left(\mathrm{D}^{\prime}\right)$ & $M_{\mathbf{k}}(\mathrm{A})$ & $M_{\mathbf{k}}(\mathrm{D})$ & $M_{\mathbf{k}}\left(\mathrm{DSD}^{\prime} \mathrm{AD}\right)$ \\
\hline TUN 1004 & 2.1 & 4.2 & 2.1 & 7.3 & 2.0 & 17.7 \\
TUN 1009 & 3.1 & 7.9 & 10.1 & 12.4 & 3.1 & 36.6 \\
TUN 1013 & 2.1 & 5.0 & 4.0 & 7.6 & 2.1 & 20.8 \\
TUN 1015 & 1.6 & 4.0 & 3.2 & 4.8 & 1.5 & 15.1 \\
\hline
\end{tabular}

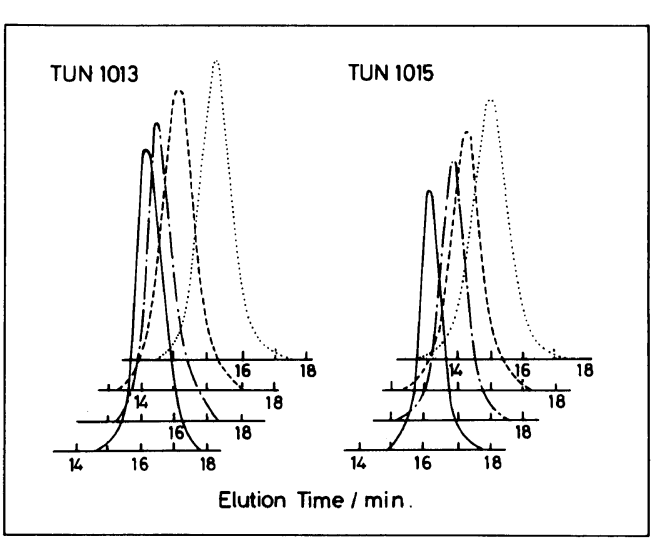

Figure 1. GPC chromatograms of samples TUN 1013 and TUN 1015 and their precursors measured with $\mathrm{GMH}_{6}$ and THF containing $5 \quad \mathrm{vol} \% \quad N, N-$ dimethylbenzylamine as the column and eluent, respectively, and detected by RI-8: full line, DS precursors; dotted-dash lines, DSD' precursors; dash lines, DSD'A precursors; dotted lines, pentablock copolymer.

$40 \mathrm{wt} \%$, and the ratio of $M_{\mathrm{k}}$ of middle diene block to those of terminal diene blocks is about 2.0. These characteristics of the pentablock copolymers meet the requisites for the film to form a three-layer lamellar structure, which is inferred from an analogy with ISIAI pentablock copolymers. ${ }^{3}$

Figure 1 shows the GPC chromatograms of samples TUN 1013 and 1015 and their precursors, which were measured by an HLC803D high-speed liquid chromatograph (Toyo Soda Mfg. Co.) equipped with a $60-\mathrm{cm} \mathrm{GMH}_{6}$ column and an RI-8 differential refractometer (Toyo Soda Mfg. Co.). The eluent was tetrahydrofuran containing $5 \quad \mathrm{vol}^{\mathrm{o}} \% \quad \mathrm{~N}, \mathrm{~N}$-di- methylbenzylamine and the flow rate was $1 \mathrm{ml} \mathrm{min} .^{-1}$ It can be seen from this figure that the chromatographic peak of each copolymer shifts in the direction of higher molecular weight as the block copolymerization proceeds and that molecular weight distributions of both of the final block copolymers are fairly narrow.

Figure 2 represents the schlieren sedimentation-boundary patterns of TUN 1013 and 1015 in tetrahydrofuran at the concentration of $0.5 \mathrm{wt} \%$. They were taken after 100 min centrifugation at $59800 \mathrm{rpm}$ at $25^{\circ} \mathrm{C}$ by use of an analytical ultracentrifuge, Beckman Spinco Model E. The single peaks without undesirable shoulders are indications of narrow molecular weight distributions of the pentablock copolymers. From Table I and Figures 1 and 2, it appears that the block copolymerizations of TUN 1013 and 1015 proceed in the ideal fashion of the living anionic polymerization.

\section{Film Preparation}

Films of about $70-\mu \mathrm{m}$ and $300 \mu \mathrm{m}$ thickness were cast on mercury from $5 \mathrm{wt} \%$ solutions of the pentablock copolymers, using benzene, dioxane, and cyclohexane as solvents. ${ }^{2}$ The solvents were evapolated slowly at $25^{\circ} \mathrm{C}$ over a period of 4-10 days under an atmosphere of dry air. The $70-\mu \mathrm{m}$ and $300 \mu \mathrm{m}$ films obtained were then dried in vacuo for about 5 and 20 days, respectively, at room temperature. The $70-\mu \mathrm{m}$ films were used for observation by electron microscopy and preparation of 


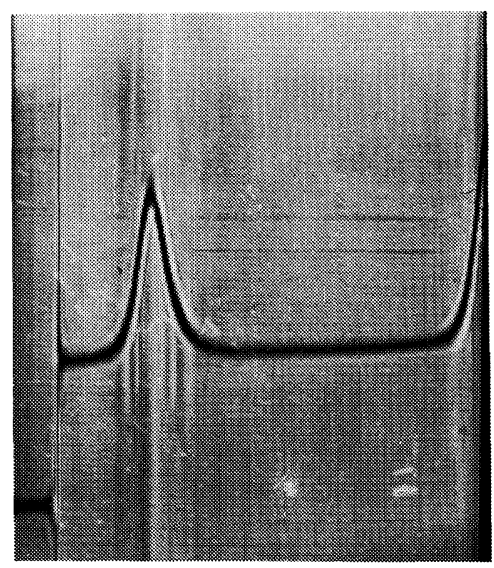

(a)

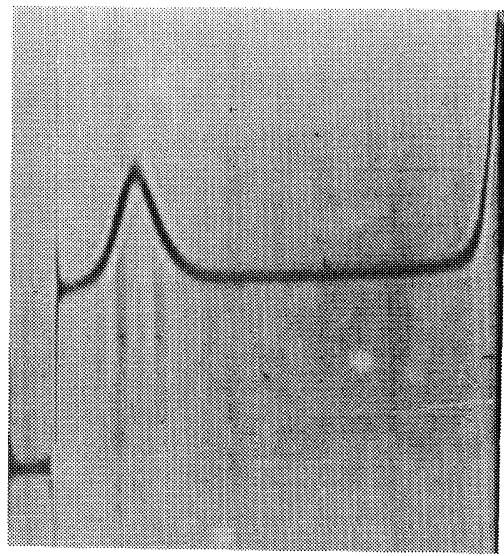

(b)

Figure 2. Schlieren sedimentation-boundary patterns of $0.5 \mathrm{wt} \%$ THF solutions of the pentablock copolymers taken after 100 min centrifugation at 59800 rpm: (a) TUN 1013; (b) TUN 1015.

charge-mosaic membranes and $300 \mu \mathrm{m}$ films for viscoelastic measurements.

Charge-mosaic membranes were prepared from the benzene-cast films of the pentablock copolymers by introducing cation-exchange and anion-exchange groups into them: first, nitrogen atoms in the A parts were quaternized with methyl iodide vapor, next, the polydiene parts (D) were cross-linked with sulfur monochloride dissolved in nitromethane at a concentration of $20 \mathrm{vol} \%$, and finally the S parts were sulfonated with chlorosulfonic acid dissolved in 1,2-dichloroethane at a concentration of $2 \mathrm{vol}^{\mathrm{o}} \%$. The details of the procedures were reported by Miyaki et al. ${ }^{6}$

\section{Observation by Electron Microscopy}

For the observation of morphologies of the films prepared from the pentablock copolymers, the as-cast and only quaternized films were exposed to a $2 \%$ aqueous solution of osmium tetroxide $\left(\mathrm{OsO}_{4}\right)$ and then cut into ultrathin sections perpendicular to the film surfaces by an ultramicrotome. The chargemosaic membranes obtained by quaternizing, cross-linking, and sulfonating the films were first immersed in a $1 \mathrm{moll}^{-1}$ solution of lead acetate, which selectively stains the sulfonated
$S$ part of the membrane, cut into ultrathin sections, and further exposed to a vapor of $\mathrm{OsO}_{4}$ in order to stain the quaternized $\mathrm{A}$ part lightly. These specimens were subjected to the observation by a Model H-600S transmission electron microscope (Hitachi, Ltd.).

\section{Viscoelastic Measurements}

Temperature dependences of the dynamic Young's modulus $E^{\prime}$, loss modulus $E^{\prime \prime}$, and $\tan \delta$ were measured with a Rheovibron DDVII-C viscoelastic spectrometer (Toyo Baldwin Co.) at a fixed frequency of $10 \mathrm{~Hz}$. The temperature was increased from 120 to $370 \mathrm{~K}$ at a rate of $1 \mathrm{~K} \mathrm{min.}^{-1}$

\section{Measurements of Ion-Exchange Capacities, Cation Transport Number, and Water Content}

Anion-exchange and cation-exchange capacities, $A_{\mathrm{m}}{ }^{-}$and $A_{\mathrm{m}}{ }^{+}$, respectively, of the charge-mosaic membrane obtained were measured by the same titrimetric methods as reported in the preceding paper. ${ }^{6}$ Cation transport number, $t_{+}$, was determined by measuring the potential difference developed between the membrane surfaces in contact with 0.01 and $0.02 \mathrm{moll}^{-1}$ aqueous solutions of $\mathrm{KCl}$. 
The water content $w_{\mathrm{m}}$ was determined from the weight of membrane that fully swelled with water and that after perfectly dried.

\section{Measurements of Solute Flows}

Flows of $\mathrm{KCl}$ and sucrose through the charge-mosaic membranes were measured by use of a dialysis cell which consisted of two water-jacketed 100-ml compartments, I and II, divided by membrane, stirring propellers in the both compartments, and Pt-black electrodes in the compartment I. The Pt-black electrodes were connected to a ZM-341 LCR meter (NF Circuit Design Block Co., Ltd.) in order to measure the conductance of the dialysand solution. Compartment I was filled with an aqueous solution containing $\mathrm{NaCl}$ and sucrose at concentrations of $0.1 \mathrm{moll}^{-1}$ and compartment II with water. The solutions in both compartments were vigorously stirred with the propellers by rotating external magnets and were thermostated at $25^{\circ} \mathrm{C}$ by circulating thermostated water into the water jackets. The flux of $\mathrm{NaCl}$ was determined from the slope of the initial tangent to the curve of $\mathrm{NaCl}$ concentration in the dialysand vs. dialysis time and that of sucrose from the sucrose concentration in the dialysand $v s$. dialysis time The effective area of the membrane was $3.14 \mathrm{~cm}^{2}$.

\section{RESULTS AND DISCUSSION}

\section{Morphologies of the Films}

Figures 3 and 4 show electron micrographs of the as-cast films of pentablock copolymers, TUN 1013 and 1015, respectively, where the light, gray, and dark regions are polystyrene (S), poly(4-VBDMA) (A), and polydiene (D) domains, respectively. The films cast from benzene and dioxane solutions have fairly regular arrays of $\mathrm{S}, \mathrm{A}$, and $\mathrm{D}$ lamellae in the order of -D-S-D-A-, although the domains of polyisoprene and polybutadiene are indistinguishable from each other by the graphs. On the other hand, the films cast from cyclohexane solutions show a chaotic structure of $S$, $\mathrm{A}$, and $\mathrm{D}$ domains, in which spherical $\mathrm{S}$ domains appear to be dispersed in the matrix of $\mathrm{A}$ and $\mathrm{D}$ domains. We could not find any substantial difference between the morphologies of the films cast from TUN 1013 and 1015 by use of the same solvent. Moreover, these features of morphology are very similar to those of ISIAI block copolymers which have S and A content nearly equal to that of TUN 1013 and 1015 and molecular architectures in which the length of the middle I block is equal to or larger than those of the terminal I blocks.

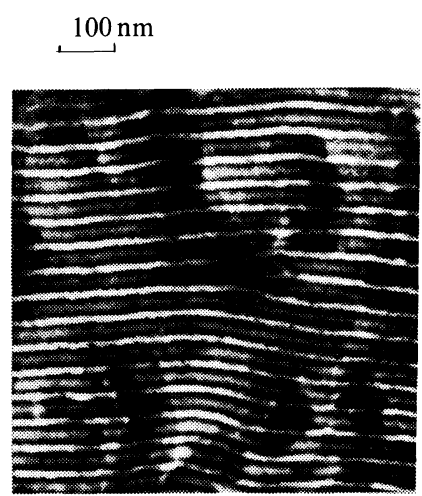

(a)

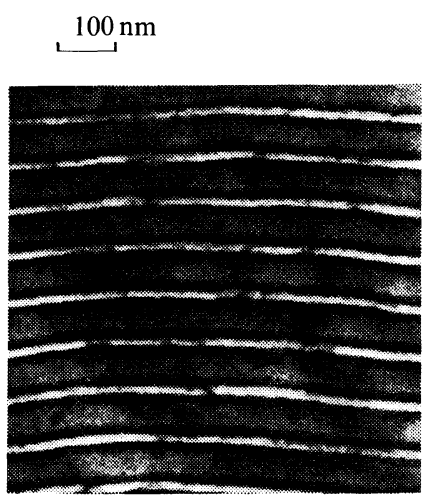

(b)

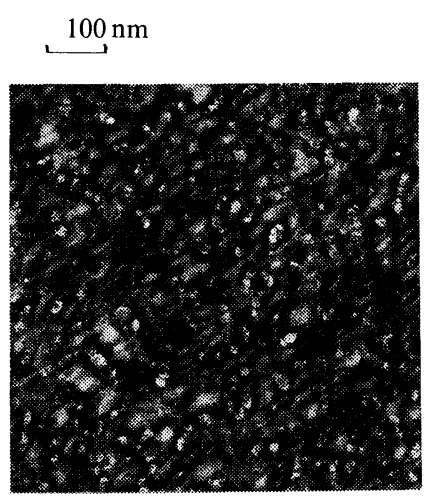

(c)

Figure 3. Electron micrographs of the as-cast films of TUN 1013 cast form benzene, dioxane, and cyclohexane solutions: (a) benzene-cast; (b) dioxane-cast; (c) cyclohexane-cast. 


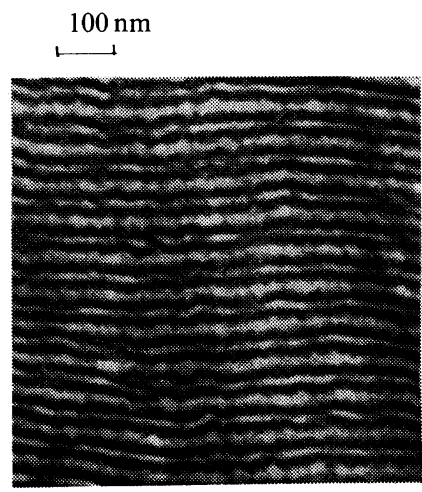

(a)

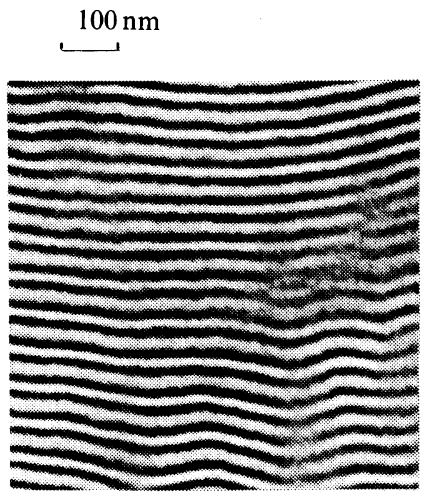

(b)

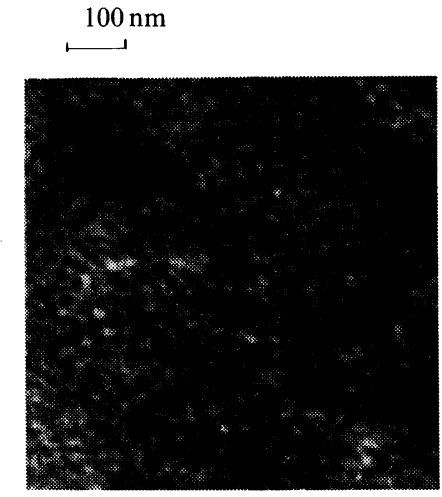

(c)

Figure 4. Electron micrographs of the as-cast films of TUN 1015 cast from benzene, dioxane, and cyclohexane solutions: (a) benzene-cast; (b) dioxane-cast; (c) cyclohexane-cast.

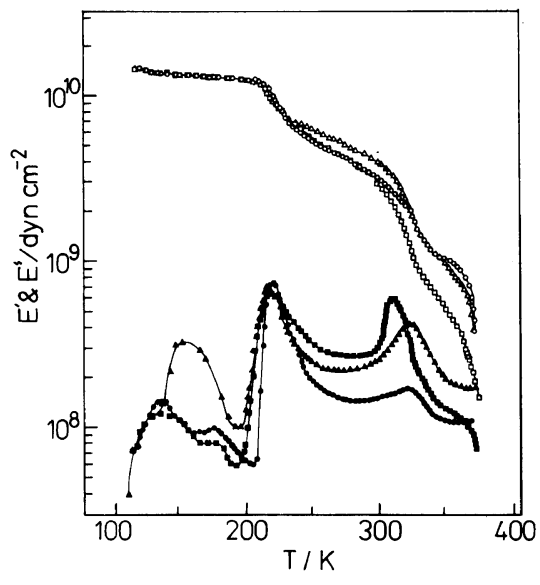

Figure 5. Temperature dependences of the dynamic Young's modulus $E^{\prime}$ and the loss modulus $E^{\prime \prime}$ of the specimens of TUN 1013 cast from various solutions: Triangles, dioxane-cast specimen; circles, benzene-cast specimen; squares, cyclohexane-cast specimen.

\section{Mechanical Properties}

The temperature dependences of the dynamic Young's modulus $E^{\prime}$ and the loss modulus $E^{\prime \prime}$ of the films of TUN 1013 cast from benzene, dioxane, and cyclohexane solutions are shown in Figure 5 and those of TUN 1015 are in Figure 6. The data for the film of ISIAI block copolymer TUN 1004 cast from a benzene solution are shown in Figure 7 for comparison. The $E^{\prime \prime}$ peaks which appear at $220-250 \mathrm{~K}$ may be assigned to the transitions

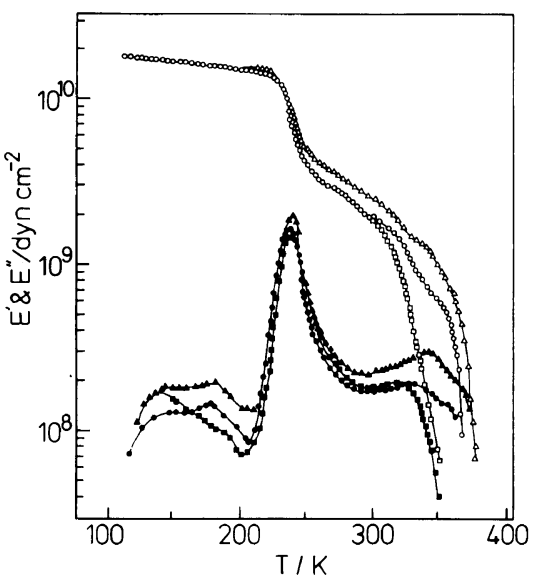

Figure 6. Temperature dependences of the dynamic Young's modulus $E^{\prime}$ and the loss modulus $E^{\prime \prime}$ of the specimens of TUN 1015 cast from various solutions. The symbols are the same as in Figure 5.

of I and B domains partly mixed with the A block of the block copolymers as pointed out by Isono et $a l^{2}$ and those which appear at $320-350 \mathrm{~K}$ to the transitions of $\mathrm{A}$ and $\mathrm{S}$ domains although they cannot be assigned clearly. In the graphs for TUN 1013 and 1015, $E^{\prime}$ of the cyclohexane-cast specimens show a more rapid decrease with increasing temperature than the other specimens. Such a feature of $E^{\prime}$ is attributable to the morphological difference between the cyclohexane-cast specimens and the others: in the former, the hard $\mathrm{S}$ 
domains are spherical and dispersed in the soft $\mathrm{D}$ matrix, while, in the latter, the $\mathrm{S}$ domains are lamellar and continuous over a large distance. This is also analogous to the situation of ISIAI block copolymers described in the preceding paper. ${ }^{3}$

These features of the temperature dependences of $E^{\prime}$ and $E^{\prime \prime}$ for TUN 1013 and 1015 above $200 \mathrm{~K}$ are very similar to those for ISIAI block copolymers. It is, however, noted in Figures 5 to 7 that each of the specimens TUN 1013 and 1015 shows a new peak in the $E^{\prime \prime}$

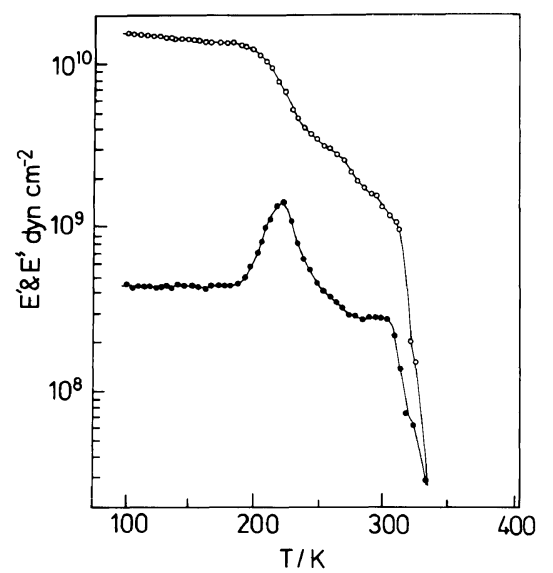

Figure 7. Temperature dependences of the dynamic Young's modulus $E^{\prime}$ and the loss modulus $E^{\prime \prime}$ of the specimen of TUN 1004 cast from a benzene solution. curve in the temperature range from 140 to $180 \mathrm{~K}$, although we cannot find any $E^{\prime}$ peak in this temperature range in the spectra of TUN 1004. The temperature region where the new peaks appear is where the glass transition of polybutadiene also appears. This fact indicates that, in the films of TUN 1013 and 1015, the B block is not perfectly mixed with the I block but at least partly segregated into its own microdomains. However, $E^{\prime}$ of every specimen of TUN 1013 and 1015 exhibits only a very slight decrease with increasing temperature below $200 \mathrm{~K}$. It can be therefore presumed that the B and I blocks of the pentablock copolymers are not segregated into different lamellae but into the same lamella even if the specimens have the three-layer lamellar structure of -D-S-D-A-.

\section{Characteristics of Charge-Mosaic Membranes}

Figure 8 shows electron micrographs of the charge-mosaic membranes prepared by chemically modifying the films cast from benzene solutions of TUN 1013 and 1015. The dark parts correspond to the cation-exchange domains consisting of sulfonated polystyrene $\left(\mathrm{S}^{-}\right)$, the gray parts to the anion-exchange domains consisting of quaternized poly(4VBDMA) $\left(\mathrm{A}^{+}\right)$, and the light parts to the

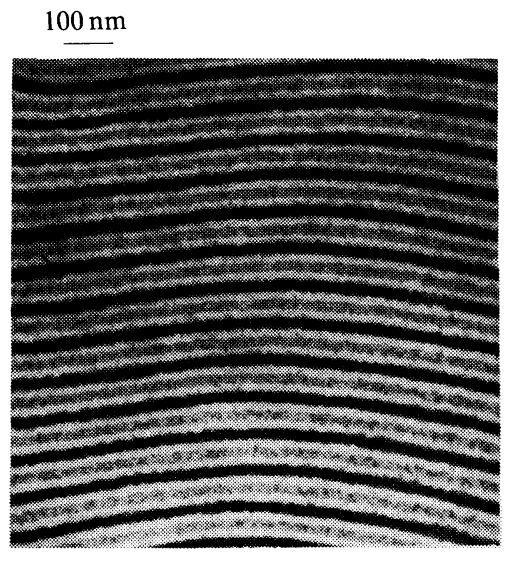

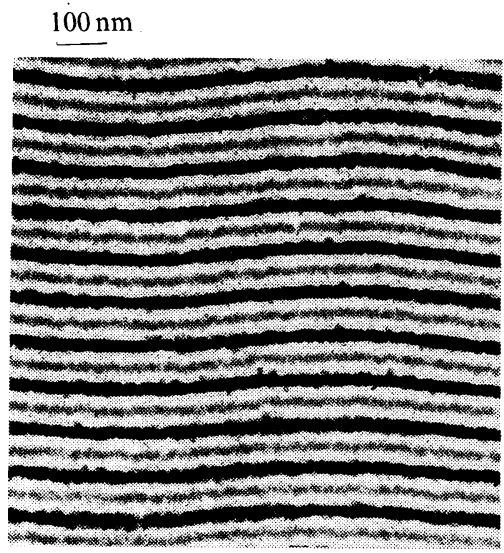

(b)

Figure 8. Electron micrographs of the charge-mosaic membranes prepared from the benzene-cast films of the pentablock copolymers: (a) TUN 1013/BZ; (b) TUN 1015/BZ. 
Table III. Cation-exchange and anion-exchange capacities, $A_{\mathrm{m}}{ }^{+}$and $A_{\mathrm{m}}{ }^{-}$, cation transport number, $t_{+}$, water content, $w_{\mathrm{m}}$, and thickness of the charge-mosaic membranes prepared from pentablock copolymers by use of benzene as the casting solvent

\begin{tabular}{lccccc}
\hline Membrane & $A_{\mathrm{m}}{ }^{+\mathrm{a}}$ & $A_{\mathrm{m}}{ }^{-\mathrm{a}}$ & $t_{+}$ & $w_{\mathrm{m}}{ }^{\mathrm{b}}$ & Thickness $^{\mathrm{c}} / \mu \mathrm{m}$ \\
\hline TUN 1013/BZ & $1.0_{6}$ & $1.0_{4}$ & 0.55 & 100 & $135 \pm 15$ \\
TUN 1015/BZ & $1.0_{4}$ & $0.8_{0}$ & 0.50 & 80 & $140 \pm 15$ \\
TUN 1004/BZ & $0.9_{2}$ & $0.5_{3}$ & 0.77 & 100 & $115 \pm 10$ \\
TUN 1009/BZ & $1.1_{0}$ & $1.0_{0}$ & 0.47 & 190 & $145 \pm 15$ \\
\hline
\end{tabular}

a In mequiv./g of dry membrane.

b In percent $\mathrm{g}$ of water/g dry membrane.

c The values for the membranes immersed in $0.5 \mathrm{moll}^{-1}$ aqueous solution of $\mathrm{NaCl}$.

dielectric domains consisting of cross-linked polydiene (D). It can be clearly seen that both of the membranes have a three-layer lamellar structure with the repeating unit -D-S ${ }^{-}-\mathrm{D}^{-} \mathrm{A}^{+}-$ and that the initial microstructure is not disrupted during the chemical modifications. Moreover, a detailed and broad investigation of the morphology by the electron microscope revealed that such regularly arranged lamellae continue over a large distance in the membranes prepared from TUN 1013 and 1015 compared with those in the membranes prepared from ISIAI block copolymers.

Cation-exchange and anion-exchange capacities $\left(A_{\mathrm{m}}{ }^{+}\right.$and ${A_{\mathrm{m}}}^{-})$, cation transport numbers $\left(t_{+}\right)$, water contents $\left(w_{\mathrm{m}}\right)$, and membrane thicknesses of the charge-mosaic membranes prepared from TUN 1013 and 1015 by use of benzene as the casting solvent are listed in Table III. Here, these values of the membranes prepared from ISIAI block copolymers TUN 1004 and 1009 are also shown for comparison. In each of the membranes TUN 1013/BZ, 1015/BZ, and 1009/BZ, $\mathrm{Am}_{\mathrm{m}}{ }^{+}$, which was about $80 \%$ of the calculated value, is nearly equal to $A_{\mathrm{m}}{ }^{-}$and $t_{+}$is close to 0.50 , the ideal value for a charge-mosaic membrane, ${ }^{8}$ while the values of $w_{\mathrm{m}}$ of TUN 1013/ $\mathrm{BZ}$ and $1015 / \mathrm{BZ}$ were appreciably lower than that of TUN 1009/BZ. Thus, fixed-charge concentrations in the ion-exchange domains of TUN 1013/BZ and 1015/BZ are higher than those of TUN 1009/BZ. On the other hand,
Table IV. Flux of $\mathrm{NaCl}, J_{\mathrm{s}}(\mathrm{NaCl})$, flux of sucrose, $J_{\mathrm{s}}$ (sucrose), and ratio, $J_{\mathrm{s}}(\mathrm{NaCl}) / J_{\mathrm{s}}$ (sucrose), for the charge-mosaic membranes in dialysis

\begin{tabular}{cllr}
\hline Membrane & $J_{\mathrm{s}}(\mathrm{NaCl})^{\mathrm{a}}$ & $J_{\mathrm{s}}{\text { (sucrose })^{\mathrm{a}}}$ & Ratio \\
\hline TUN 1013/BZ & $8.5 \times 10^{-8}$ & $6.1 \times 10^{-10}$ & 140 \\
TUN 1015/BZ & $9.0 \times 10^{-8}$ & $5.6 \times 10^{-10}$ & 160 \\
TUN 1004/BZ & $8.3 \times 10^{-8}$ & $1.3 \times 10^{-9}$ & 64 \\
TUN 1009/BZ & $1.2 \times 10^{-7}$ & $1.2 \times 10^{-9}$ & 100 \\
\hline
\end{tabular}

${ }^{\text {a }}$ In $\mathrm{mol} \mathrm{cm}{ }^{-2} \mathrm{~s}$.

in the membrane TUN $1004 / \mathrm{BZ}, A_{\mathrm{m}}{ }^{+}$is appreciably larger than $A_{\mathrm{m}}{ }^{-}$and $t_{+}$is much larger than 0.50 . It is clear from the data in Table III that membranes TUN 1013/BZ and 1015/BZ have more suitable properties as charge-mosaic membranes than the other membranes in Table III although the molecular weights of the component blocks of the starting pentablock copolymers TUN 1013 and 1015 are considerably lower than those of TUN 1009 and close to those of TUN 1004.

In Table IV are represented the results of dialysis experiments with the charge-mosaic membranes shown in Table III. As predicted, every membrane shown is much more permeable to the ionized inorganic species, $\mathrm{NaCl}$, than the unionized organic species, sucrose. It is noted in this table that the ratio of flux of $\mathrm{NaCl}$ to that of sucrose for TUN 1013/BZ and $1015 / \mathrm{BZ}$ is higher than those for the other membranes, indicating that performance of a charge-mosaic membrane can be improved by 
employing different monomers to constitute, respectively, the middle block and the terminal blocks of the starting pentablock copolymer.

\section{Molecular Arrangement}

When a pentablock copolymer of the DSD'AD type generates the three-layer lamellar structure of the repeating unit -D-S-D-A-, various modes of molecular arrangement are conceivable. $^{2,3}$ Three typical types of the modes are shows in Figure 9. In types a and $b$, the chain ends of each of the component blocks, S and A, are anchored to the different adjacent neutral domains consisting of the $\mathrm{D}$ and $\mathrm{D}^{\prime}$ blocks, while in type $\mathrm{c}$, they are anchored to the same adjacent neutral domain. Therefore, the resulting chargemosaic membrane would be tougher and exhibit a better perfomance when the starting block copolymer has the molecular arrangement of $a$ and $b$ than $c$. If a pentablock copolymer of the ISBAI or BSIAB type has a molecular arrangement of type a, $E^{\prime}$ will show a considerable decrease with increasing temperature in the region near the glass transition temperature of polybutadiene. However, this is not the case with our samples TUN 1013 and 1015 as shown in Figures 5 and 6. In addition to this fact, the results of observation by a electron microscope and dialysis experiments suggest that the pentablock copolymers of the ISBAI and BSIAB types can be arranged in the mode of type $b$ more easily than that of the ISIAI type.

Acknowledgment. The authors are grateful to Prof. Dr. T. Nose and Dr. J. Watanabe, Department of Polymer Chemistry, Tokyo Institute of Techology, for their advice and assistance in carring out the viscoelastic measurements, and to Dr. A. Akimoto, Dr. T. Seita and Dr. S. Matsushita, Toyo Soda Mfg. Co., Ltd., Ayase and Shin-Nanyo, for their encourgement and useful suggestions. This work was supported by a Gant-in-Aid for Scientific Reseach from the Ministry of

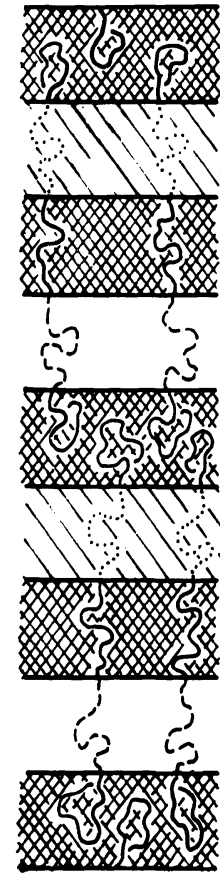

(a)

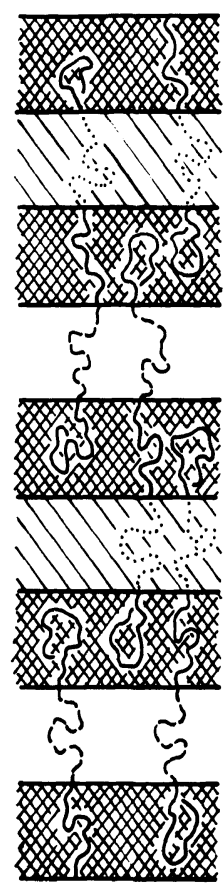

(b)

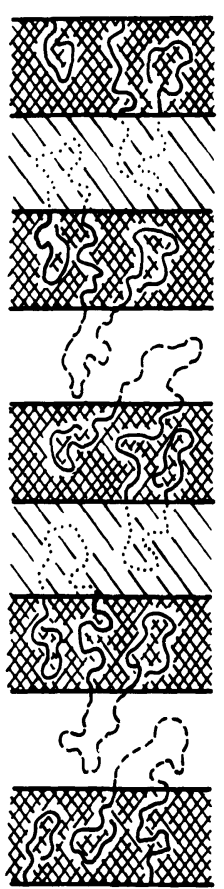

(c)
Figure 9. Spatial arrangements of the pentablock copolymers; reticulated parts, polydiene domains: Shaded parts, polystyrene domains; white parts, poly(4VBDMA) domains.

Education, Science and Culture of Japan.

\section{REFERENCES}

1. H. Funabashi, Y. Miyamoto, Y. Isono, T. Fujimoto, Y. Matsushita, and M. Nagasawa, Macromolecules, 16, 1 (1983).

2. Y. Isono, H. Tanisugi, K. Endo, T. Fujimoto, H. Hasegawa, T. Hashimoto, and H. Kawai, Macromolecules, 16, 5 (1983).

3. Y. Miyaki, M. Iwata, Y. Fujita, H. Tanisugi, Y. Isono, and H. Fujimoto, Macromolecules, 17, 1907 (1984).

4. T. Fujimoto, K. Ohkoshi, Y. Miyaki, and M. Nagasawa, Science, 224, 74 (1984).

5. T. Fujimoto, K. Ohkoshi, Y. Miyaki, and M. Nagasawa, J. Membr. Sci., 20, 313 (1984).

6. Y. Miyaki, H. Nagamatsu, M. Iwata, K. Ohkoshi, K. Se, and T. Fujimoto, Macromolecules, 17, 2231 (1984).

7. Y. Matsushita, H. Choshi, T. Fujimoto, and M. Nagasawa, Macromolecules, 13, 1053 (1980).

8. O. Kedem and A. Katchalsky, Trans. Faraday Soc., 59, 1918, 1931 (1963). 